\title{
Designing and Evaluating a Computational Thinking Course for K-12 Brazilian Educators
}

\author{
Eduardo C. Oliveira ${ }^{1}$, Roberto A. Bittencourt ${ }^{1}$, Rosaria P. Trindade ${ }^{1}$ \\ ${ }^{1}$ UEFS - Universidade Estadual de Feira de Santana \\ Av. Transnordestina, s/n, Novo Horizonte \\ Feira de Santana - BA, Brasil - 44036-900 \\ educdoliveira@gmail.com, roberto@uefs.br, rosapt@uefs.br
}

\begin{abstract}
This paper evaluates an online Computational Thinking (CT) course for $\mathrm{K}-12$ Brazilian educators. Considering the relevance of CT in current society and given that most K-12 teachers in Brazil still do not know the basics of CT, we designed and implemented an online course to provide qualification in CT and Programming fundamentals. We also aimed to assess educators' attitudes towards Computing, how their motivation were manifested over the intervention, and the correlation between motivation and attitudes. The outcomes suggest that learners' attitudes towards Computing has become more positive after the course, as well as indicate a high degree of participants' motivation during the workshop.
\end{abstract}

Resumo. Este artigo avalia um curso online de Pensamento Computacional (PC) para professores da Educação Básica no Brasil. Considerando a relevância de PC na sociedade atual e que a maior parte dos educadores brasileiros ainda não conhece os fundamentos de PC, nós desenvolvemos um curso online para prover qualificação básica em PC e Programação. Nós também tivemos como objetivo avaliar atitudes dos educadores em relação à Computação, analisar como a motivação se expressou durante a intervenção, além de realizar uma correlação entre atitudes e motivação. Os resultados indicam que as atitudes dos participantes em relação à Computação se tornaram mais positivas após o curso, bem como sugerem que o grau de motivação permaneceu alto ao longo da oficina.

\section{Introduction}

Over the last decades, the contemporary world has been facing new challenges with the rise of digital devices. Since modern technologies have been able to produce solutions to a range of routine problems, researchers have been arguing on how humans can learn and use these skills. Considering this framework, Wing has established the idea of Computational Thinking (CT), which is, in her words, a skill set that involves systems design, problem solving and abstraction processes, based on the core fundamentals of Computer Science [Wing 2006].

Despite CT has its principles relying on Computer Science, it is suitable for everyone, not being restricted to computer scientists. Typical educational activities such as reading, writing and solving arithmetic operations can be boosted by CT. Thus, the academic community has been encouraging experiences over the world aiming to evaluate the impact of CT on K-12 educators. 
VIII Congresso Brasileiro de Informática na Educação (CBIE 2019)

Anais dos Workshops do VIII Congresso Brasileiro de Informática na Educação (WCBIE 2019)

Yadav et al. have implemented a project describing how CT modules can be incorporated into an educational psychology course for pre-service teachers in the United States [Yadav et al. 2014]. Kaila et al. have developed a programming course in Finland for teacher education students, having CT as a learning goal [Kaila et al. 2018]. In Brazil, Silva et al. have also designed a CT teaching project for K-12 teachers [Silva et al. 2017].

At present, the development of suitable CT qualifications for K-12 educators is an issue. CT and its potential are not put to use by a large section of the Brazilian teaching community. It is possible to find CS training programs for K-12 educators, but most teachers still do not know the basics of CT or how it can contribute to their classes. Hence, it is essential to present CT to K-12 educators. Additionally, supplying these educators with proper conditions to handle CT fundamentals is also needed.

In this context, this study aimed to design and implement an online course on CT and Programming for K-12 educators, as well as to evaluate participants' attitudes towards $\mathrm{CT}$ and motivation. The research questions that led this study are:

RQ1. Are teachers' attitudes towards CT modified after the course? If so, by how much?

RQ2. How is teachers' motivation expressed during the course?

RQ3. What is the correlation between teachers' motivation and their attitudes towards CT?

\section{Background}

Here we describe the background needed for this paper and some related work.

\subsection{Computational Thinking}

The definition of Computational Thinking (CT) has been often updated since its arise in 2006. CT was initially pictured as an umbrella that, based on Computer Science (CS) fundamentals, covers from systems design to abstraction and problem solving processes [Wing 2006]. CT is currently defined as the thought process that involves formulating problems and their solutions. These solutions are reproduced in such a way that both humans and machines are able to comprehend.

Computational Thinking also has a key element in its definition, which is the indication that it should be reached by everyone involved in an educational scenario, such as teachers and students [Wing 2006]. A proper approach for this is to carry CT to the classroom. For example, CT could be applied by K-12 teachers in a range of modules that request reasoning, being expressed in class through the insertion of problem-solving activities [Barr and Stephenson 2011]. First, this could allow students to handle different means to solve problems, to become comfortable with trial and error, and to be in a suitable atmosphere of discovering things in groups. At last, students could comprehend that solutions are often expressed in multiple forms, and cultivate good expectations when designing these solutions.

\subsection{K-12 Teacher Training in Computing}

Researchers have been arguing on the need to qualify teachers in Computational Thinking fundamentals. Barr and Stephenson (2011) have indicated short-term ideas to supply 
VIII Congresso Brasileiro de Informática na Educação (CBIE 2019)

Anais dos Workshops do VIII Congresso Brasileiro de Informática na Educação (WCBIE 2019)

educators with an adequate preparation for applying CT in K-12 education, including the establishment of a network between Computer Science programs with teachers, as well as the opportunity to provide educators with professional preparation offered by a community experienced in CT. These approaches could extend the role of CT in non-CS disciplines and contribute to making new relevant materials on CT in K-12 education.

Furthermore, Yadav et al. (2014) have suggested that students could learn Computational Thinking by watching their teachers, and developing their own methods to solve problems in the following steps. Currently, there are a variety of approaches towards Computing in K-12 education. In countries like Australia, Finland, Israel, New Zealand, the United Kingdom and the United States, curriculum analysts have updated their standards and curricula to elicit CS and CT ideas [Gal-Ezer and Stephenson 2014].

\subsection{Related Work}

Efforts have been made in the latest years to prepare K-12 educators in Computational Thinking and Computer Science. For instance, Yadav et al. (2014) have implemented a project to incorporate CT into an educational psychology course for pre-service teachers in the United States. They aimed to evaluate teachers' attitudes towards Computing and the impact of CT modules on the course. The outcomes showed that the work could increase educators' understanding about CT and how to use it in their classrooms.

In Finland, Kaila et al. (2018) have run a project for teacher education students. Their goal was to teach educational approaches, tools and content knowledge on Programming and CT principles. Results revealed that the greater part of participants completed the course, manifesting positive feedback from the lessons and tending to change their attitudes towards Programming and CT.

Furthermore, Santos et al. (2017) have studied Computing Teacher Education preservice programs in Brazil. Their goal was to spot and discuss the main challenges faced by Computing Teacher Education students. Results from this work indicated a lack of integration between theoretical and practical approaches on teacher qualification.

Other studies examined K-12 pre-service teacher preparation in Computing, such as Gal-Ezer and Stephenson (2014) and Santos et al. (2017), being similar to our work. Nonetheless, we take a step ahead to design and run an online short-term course for educators. In addition, our work is also comparable to the work of Yadav et al. (2014) and Kaila et al. (2018), since our goal is to teach Computational Thinking concepts. However, our audience is not pre-service teachers, but professional K-12 educators.

\section{Methodology}

We split this section into subsections as follows: Intervention, describing the workshop planning and its tools; Participants, providing further detail about the students enrolled in the course; Data Collection and Analysis, explaining how the crucial information for this research was gathered and providing a view about the analysis performed to obtain the most relevant results.

\subsection{Intervention}

The intervention ran in the second semester of 2018 through an online workshop for K-12 educators. The course was carried out in five weeks and used Scratch 2.0 as the programming platform and Google Classroom as the virtual learning environment. 
VIII Congresso Brasileiro de Informática na Educação (CBIE 2019)

Anais dos Workshops do VIII Congresso Brasileiro de Informática na Educação (WCBIE 2019)

The workshop was split into three modules, consisting mostly of practical activities, uploaded video lessons and group conversations on Google Classroom. Unit 1 ran in the first week and introduced our goals in this project as well as the tools to be used. Course members were also presented to the core Computational Thinking (CT) fundamentals, including the steps used to solve problems. At the end of Week 1, participants were requested to argue on the application of CT principles in K-12 education.

Unit 2 aimed to explore Scratch projects and CT fundamentals: Algorithms, Parallelism and Abstraction. Tutorial lessons were uploaded concerning the existing command groups on Scratch over three weeks. Week 2 focused on teaching how to design interactive stories using mainly Looks, Events and basic Control blocks. Lessons in Week 3 were dedicated to show how to create animations by handling Data, Operators, Motion and advanced Control blocks. In Week 4, videos guided the development of a small game using Sensing and advanced Events blocks, along with creating particular pieces of scripts through the More Blocks tab. Course members were required to implement a Scratch project at the end of each week in Unit 2, including in the activity the blocks just learned.

Computer Science principles were presented in Unit 3, linking them to blocks previously used on Scratch. Hence, in the last week, learners were able to comprehend Programming basics, such as logical operations, sequences, parallelism, select and control structures, and could expand their understanding on CT. Yet, they were introduced to variables and their association with Data blocks, as well as functions and their connection to individual blocks on Scratch. Table 1 shows the course planning, outlining activities, goals and the content knowledge taught in the course.

Table 1. Course Planning

\begin{tabular}{c|c|c|c}
\hline Class & Activity & Goals & Content \\
\hline Week 1 & $\begin{array}{c}\text { Introducing workshop planning and having a } \\
\text { group discussion about CT and Scratch }\end{array}$ & $\begin{array}{c}\text { Obtain an introductory understanding on CT } \\
\text { applications in K-12 education }\end{array}$ & $\begin{array}{c}\text { Computational Thinking principles; } \\
\text { CT in K-12 education; } \\
\text { Scratch download and setup }\end{array}$ \\
\hline Week 2 & $\begin{array}{c}\text { Implementing an interactive story on Scratch } \\
\text { by managing at least two sprites }\end{array}$ & $\begin{array}{c}\text { Comprehend the use of elementary Scratch } \\
\text { blocks and tools to develop a project }\end{array}$ & $\begin{array}{c}\text { Sprite or background insertion; } \\
\text { Basic Control blocks; } \\
\text { CT: Algorithms }\end{array}$ \\
\hline Week 3 & $\begin{array}{c}\text { Creating animations on Scratch } \\
\text { that reproduces routine situations }\end{array}$ & $\begin{array}{c}\text { Apply logical operations and control } \\
\text { blocks to implement average level projects }\end{array}$ & $\begin{array}{c}\text { Motion blocks; } \\
\text { Advanced Control blocks; Variables }\end{array}$ \\
\hline Week 4 & $\begin{array}{c}\text { Designing a game on Scratch that incorporates } \\
\text { time and score factors }\end{array}$ & $\begin{array}{c}\text { Learn how to merge advanced Scratch blocks } \\
\text { to develop a high level project }\end{array}$ & $\begin{array}{c}\text { Sensing blocks; } \\
\text { Sprite communication; } \\
\text { CT: Abstraction }\end{array}$ \\
\hline Week 5 & Presenting Programming fundamentals & $\begin{array}{c}\text { Associate CT principles with the examples } \\
\text { seen on Scratch to study Programming concepts }\end{array}$ & $\begin{array}{c}\text { CT principles review; } \\
\text { Sequences; Conditions; } \\
\text { Logical operators; Variables }\end{array}$ \\
\hline
\end{tabular}

\subsection{Participants}

The first 20 online submissions with full consent to enroll in the research were registered in the course. The participants' mean age was 38.8, with a standard deviation of 9.1. Concerning their gender, the intervention had a total of $70 \%$ female and $30 \%$ of male members. In addition, $40 \%$ of learners held undergraduate degree in Education, while degrees in Biology, History and Mathematics figures were $10 \%$ each. Most participants $(65 \%)$ were elementary and middle school teachers, whilst $15 \%$ were high school teachers, and $20 \%$ worked with both educational stages. 
VIII Congresso Brasileiro de Informática na Educação (CBIE 2019)

Anais dos Workshops do VIII Congresso Brasileiro de Informática na Educação (WCBIE 2019)

\subsection{Data Collection and Analysis}

We asked participants to answer a survey on Google Forms before the start of the course. This survey regarded their attitudes towards CT and CS and it was also applied after the workshop. It relied on Yadav et al.'s [Yadav et al. 2014] and Hoegh and Moskal's [Hoegh and Moskal 2009] studies, combining the following categories: From the survey in [Yadav et al. 2014], we picked Definition and Classroom categories; from the questionnaire in [Hoegh and Moskal 2009], we selected Confidence, Interest and Usefulness constructs. These constructs and their statements are found in the companion web site ${ }^{1}$. Course members also responded a second questionnaire after the course, regarding how their motivation were expressed along the intervention, and included 36 questions from Kellers' Instructional Materials Motivation Survey (IMMS) [Keller 1987]. These statements are also seen in the companion web site.

To produce inferences, data normality was tested through a Shapiro-Wilk test. Although normality was assured for all categories from the motivation survey, this was not confirmed in constructs from the first questionnaire, which led to a non-parametric analysis for attitudes survey. Each category figure was gathered by calculating the mean value from its respective statements. Later, a Wilcoxon rank-sum test was used to compare the differences between attitudes constructs pre- and post-course, aiming to evaluating how attitudes towards Computing were modified. Furthermore, Spearman's rank correlation coefficient was used to determine the correlation between constructs from both attitudes and motivation questionnaires, including correlations from categories in the same survey. Lastly, box plots were generated to reinforce the visual outcomes.

\section{Results}

Here we present the results from the surveys. The outcomes are split into three subsections, regarding RQ1, RQ2 and RQ3 ${ }^{23}$.

\subsection{Attitudes towards Computing}

First, we tried to answer RQ1: Are teachers' attitudes towards CT modified after the course? If so, by how much? by assessing participants' attitudes towards Computing indicated in five categories in the pre- and post-course questionnaires. These constructs were tested for normality through Shapiro-Wilk test. Only the Definition (0.21) and Usefulness (0.36) categories had normally distributed figures in the pre-intervention survey, whereas none of the five constructs had a normal distribution in the post-intervention survey.

Hence, non-parametric hypothesis tests were applied to compare the differences between the constructs before and after the course. The Wilcoxon test was used, considering median weights from all categories. Applying this test, we found p-values lower than the significance level of 0.05 in all constructs. For analysis reasons, Agree and Strongly Agree submissions are considered positive marks, whilst Disagree and Strongly Disagree submissions are negative answers.

\footnotetext{
${ }^{1}$ https://sites.google.com/site/fie2019teachers/

${ }^{2}$ For space reasons, all the stacked bar graphs for the categories used in this work are available in the companion web site.

${ }^{3}$ For visual purposes, the negative phrased statements were reversely scored and indicated by $\mathrm{R}$ as suffix in all stacked bars.
} 
VIII Congresso Brasileiro de Informática na Educação (CBIE 2019)

Anais dos Workshops do VIII Congresso Brasileiro de Informática na Educação (WCBIE 2019)

In Figure 1, box plots are shown for each construct before and after the workshop, given a 4-point Likert Scale, from Strongly Disagree (lowest rate) to Strongly Agree (highest rate). From box plots on the left side, we noticed that Classroom values were already high and concentrated, as its median was 3.5 and had an interquartile range (IQR) of 0.5 . Despite having larger variation ranges, the median calculated for the other categories was also high (3.0). However, in post-course box plots seen on the right side, we perceived a sensitive rise in median values and narrower interquartile ranges. The median for all constructs was 4.0, and the Definition category had the greatest IQR (0.75).

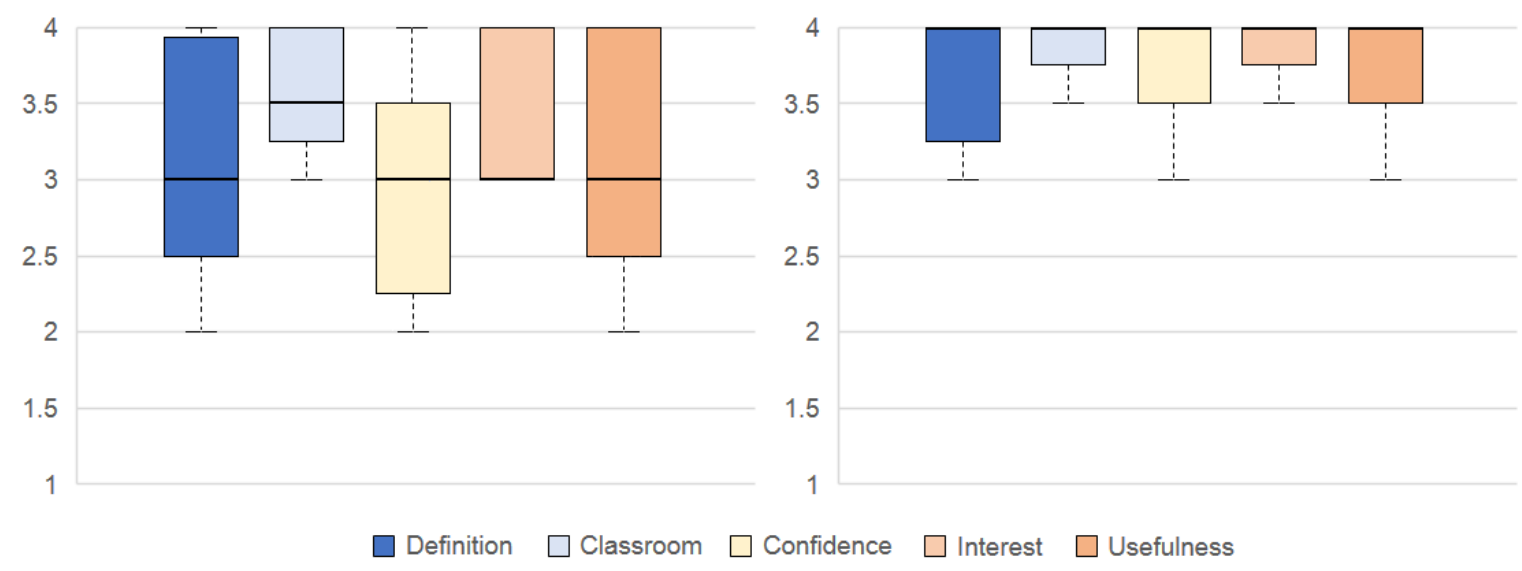

Figure 1. Box Plots - Pre-Workshop and Post-Workshop Attitudes Constructs

\subsection{Motivation}

With another survey, we attempted to answer RQ2: How is teachers' motivation expressed during the course? by computing data manifested in four motivation constructs, and applied after the workshop. These categories were also tested for normality through Shapiro-Wilk test. A parametric analysis was carried out, since all categories had normally distributed figures. For analysis purposes, Mostly True and Very True submissions are considered positive responses, whereas Slightly True and Not True submissions are negative marks, and Moderately True are seen as neutral answers.

From the outcomes for this survey, we found a lower median figure in the Confidence construct (3.72) compared to the other categories, namely Satisfaction (4.33), Relevance (4.22) and Attention (4.16). On the other hand, we found similar IQR values for all constructs. The Satisfaction category had the highest IQR number (0.45), followed by Attention and Confidence constructs (0.44 and 0.39), while Relevance had the lowest IQR value (0.22). A synthesis of these results is seen in Figure 2, given a 5-point Likert scale, from Not True (lowest rate) to Very True (highest rate).

\subsection{Correlation between Attitudes towards Computing and Motivation}

After obtaining data from educators' attitudes towards Computing and their motivation manifested during the course, we sought an answer to RQ3: What is the correlation between teachers' motivation and their attitudes towards CT?. Given that most attitudes categories were not normally distributed, we used Spearman's rank correlation coefficient for a non-parametric analysis. Table 2 describes the correlation outcomes. 
VIII Congresso Brasileiro de Informática na Educação (CBIE 2019)

Anais dos Workshops do VIII Congresso Brasileiro de Informática na Educação (WCBIE 2019)

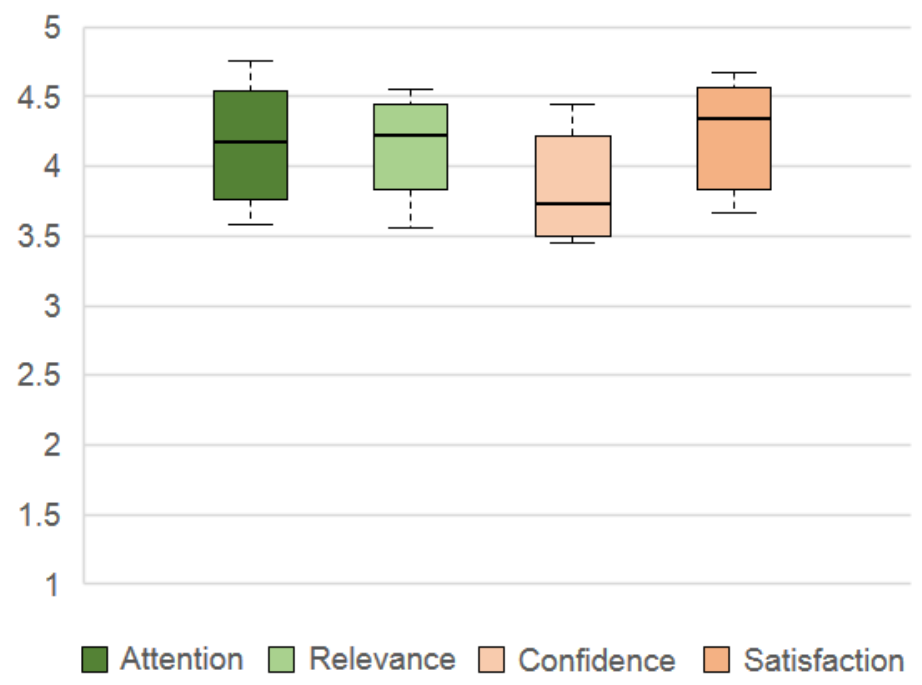

Figure 2. Box Plots - Motivational Constructs

Excluding self-associations, we noticed a substantial number of strong and medium correlations among constructs. Among the four motivation constructs (Group 1) [Keller 1987], we found a large association between Relevance and Confidence (0.78), Confidence and Satisfaction (0.74), Relevance and Satisfaction (0.62), Attention and Relevance $(0.5)$. The remaining correlations within this group were also near a high level (0.48 and 0.49).

Between the categories based on Yadav et al.'s study [Yadav et al. 2014] (Group 2), namely Definition of CT and CT in Classroom, we also found a strong correlation (0.53). Among categories from Hoegh and Moskal's [Hoegh and Moskal 2009] study (Group 3), we found a large association (0.59) between Confidence and Interest, along with medium correlations ( 0.49 and 0.43 ) between these categories and Usefulness.

We also observed strong and medium associations between constructs from different groups. Interest and Confidence (from Group 3) categories had large positive correlations with Relevance (0.61 and 0.51). Furthermore, Confidence (from Group 1) and Interest had a medium association (0.48). Finally, we found medium negative trends of -0.46 between Satisfaction and Usefulness, and -0.30 between Definition and Confidence (Group 3).

Table 2. Correlations between Attitudes and Motivation categories ${ }^{4}$

\begin{tabular}{|c|c|c|c|c|c|c|c|c|c|}
\hline Attention & $1(.000)^{* * *}$ & & & & & & & & \\
\hline Relevance & $.5(.06)$ & $1(.000)^{* * * *}$ & & & & & & & \\
\hline Confidence & $.49(.07)$ & $.78(.000)^{* * *}$ & $1(.000)^{* * *}$ & & & & & & \\
\hline Satisfaction & $.48(.07)$ & $.62(.01)^{*}$ & $.74(.002)^{* *}$ & $1(.000)^{* * *}$ & & & & & \\
\hline Definition & $.17(.53)$ & $-.21(.45)$ & $-.14(.61)$ & $-.21(.45)$ & $1(.000)^{* * *}$ & & & & \\
\hline Classroom & $.12(.66)$ & $-.15(.59)$ & $.05(.86)$ & $-.23(.42)$ & $.53(.04)^{*}$ & $1(.000) * * *$ & & & \\
\hline Confidence & $.12(.68)$ & $.51(.06)$ & $.22(.44)$ & $-.08(.77)$ & $-.3(.29)$ & $-.25(.38)$ & $1(.000)^{* * *}$ & & \\
\hline Interest & $-.08(.77)$ & $.61(.02)^{*}$ & $.48(.07)$ & $.11(.68)$ & $-.27(.34)$ & $-.02(.92)$ & $.59(.02)^{*}$ & $1(.000)^{* * *}$ & \\
\hline Usefulness & $-.02(.94)$ & $.12(.66)$ & $-.07(.8)$ & $-.46(.09)$ & $.13(.64)$ & $.21(.46)$ & $.49(.07)$ & $.43(.11)$ & $1(.000)^{* * * *}$ \\
\hline Category & Attention & Relevance & Confidence & Satisfaction & Definition & Classroom & Confidence & Interest & Usefulness \\
\hline
\end{tabular}

\footnotetext{
${ }^{4}$ One $*$ symbol represents $90 \%$ of significance (p-value lower than .05 ), whilst $* *$ represents $95 \%$ of significance (p-value lower than .01) and $* * *$ represents $99 \%$ of significance (p-value smaller than .001).
} 
VIII Congresso Brasileiro de Informática na Educação (CBIE 2019)

Anais dos Workshops do VIII Congresso Brasileiro de Informática na Educação (WCBIE 2019)

\section{Discussion}

Given the outcomes described in previous section, we could answer our research questions. Regarding RQ1, results reveal that all constructs had higher median figures after the intervention. Our results from RQ1 are similar to the findings from Yadav et. al's study [Yadav et al. 2014], such as in their statement concerning participants' comprehension about abstraction. This means that our work could contribute to participants' understanding towards Computing and Computational Thinking (CT).

From results found in RQ2, the Relevance category had the highest median figures among motivation categories. We highlight that learners indicated a solid association between their career goals and Computing skills, specially because these skills are increasingly demanded in current society. In addition, participants' levels of interest in CT were already high before the course, considering that enrollment in the course was voluntary. However, their knowledge of CT was poor at the beginning of the workshop. Thus, our initial lessons were designed to explore and boost the comprehension of CT principles.

Both surveys in RQ1 and RQ2 measured participants' confidence and had corresponding results. In our questionnaires, we raised questions concerning their confidence to design Scratch projects in different moments of the intervention. While learners expressed moderate belief in themselves in Week 1, their confidence had a substantial growth in the following weeks. Hence, lessons and proposed activities had a proper difficulty level and could keep participants motivated to complete projects.

Results from RQ3 indicate a considerable correlation between specific constructs from different groups. Strong associations between categories within the same group were already expected, like Confidence and Satisfaction, from ARCS and combined with Keller's study [Keller 1987]. Nevertheless, we also found valuable correlations among categories from separate works. As an example, Relevance (ARCS) and Interest (based on Hoegh and Moskal's work [Hoegh and Moskal 2009]) had a large positive association. Therefore, teachers interested in incorporating CT into their lessons and working with solving-problem projects noticed a higher relevance in our intervention. Additionally, Satisfaction (from ARCS) and Usefulness (from Hoegh and Moskal's) had a medium negative correlation. Thus, even though most participants revealed good levels of satisfaction throughout the workshop, it may not be compulsorily connected with their career goals.

Threats to validity. The fact that teachers might be spontaneously motivated in enrolling in educational courses could be seen as a confounding factor in our study. Nonetheless, we did not attempt to modify educators' motivation. We showed that this kind of experience has potential to elicit high degrees of motivation over the intervention, as well as to power teachers' attitudes towards CT. Moreover, this case study does not aim to extrapolate outcomes to a different audience, but it tries to analyze different aspects of motivation and attitudes in the context of an online course on CT and programming for K-12 educators.

\section{Conclusion}

This study aimed to design an online course introducing Computational Thinking (CT) to K-12 educators, focused on evaluating their motivation and attitudes towards Computing. 
VIII Congresso Brasileiro de Informática na Educação (CBIE 2019)

Anais dos Workshops do VIII Congresso Brasileiro de Informática na Educação (WCBIE 2019)

We developed a five-week Computing course, using Scratch 2.0 as programming platform and Google Classroom as virtual learning environment. Twenty K-12 educators from the state of Bahia, Brazil, voluntarily registered in the workshop by filling in an online form.

From results obtained in this work, we infer that it is relevant for Computing researchers to design CT courses considering participants' motivation and attitudes towards Computing. A well-designed course on CT can power a set of educators' skills, such as confidence, satisfaction and interest in Computing. Therefore, it is possible to extend CT to undergraduate courses in Education and schools with this kind of intervention, ultimately contributing to the rise of Computational Thinking in K-12 education.

Supported by this study, we propose the introduction of Computational Thinking courses in undergraduate degree programs in Education as future work. Furthermore, we recommend additional research focusing on the correlation between participants' attitudes and motivation with their learning of CT and CS. At last, we suggest an expansion of this study in a qualitative approach to better analyze issues associated with the development of the course.

\section{References}

Barr, V. and Stephenson, C. (2011). Bringing Computational Thinking to K-12: What is Involved and What is the Role of the Computer Science Education Community? ACM Inroads, 2(1):48-54.

Gal-Ezer, J. and Stephenson, C. (2014). A Tale of Two Countries: Successes and Challenges in K-12 Computer Science Education in Israel and the United States. ACM Trans. Comput. Educ., 14(2):8:1-8:18.

Hoegh, A. and Moskal, B. M. (2009). Examining science and engineering students' attitudes toward computer science. In Proceedings of the 39th IEEE International Conference on Frontiers in Education Conference, FIE'09, pages 1306-1311, Piscataway, NJ, USA. IEEE Press.

Kaila, E., Laakso, M., and Kurvinen, E. (2018). Teaching future teachers to code : Programming and computational thinking for teacher students. In 201841 st International Convention on Information and Communication Technology, Electronics and Microelectronics (MIPRO), pages 0677-0682. IEEE.

Keller, J. M. (1987). Development and use of the ARCS model of instructional design. Journal of instructional development, 10(3):2-10.

Santos, W. O., Silva, C., and Hinterholz, L. (2017). Licenciatura em computação: Desafios e oportunidades na perspectiva do estudante. In Anais do Workshop de Informática na Escola, page 885.

Silva, V., da Silva, L. L., and França, R. (2017). Pensamento computacional na formação de professores: Experiências e desafios encontrados no ensino da computação em escolas públicas. In Anais do Workshop de Informática na Escola.

Wing, J. M. (2006). Computational thinking. Commun. ACM, 49(3):33-35.

Yadav, A., Mayfield, C., Zhou, N., Hambrusch, S., and Korb, J. T. (2014). Computational thinking in elementary and secondary teacher education. Trans. Comput. Educ., 14(1):5:1-5:16. 